\title{
Renal length in a healthy Sri Lankan adult population - Sonographic study
}

\author{
Kodikara I I , Gamage DTK ${ }^{2}$, Nilmini KWGP ${ }^{1}$, Nanayakkara BG ${ }^{1}$, Ilayperuma I ${ }^{1}$ \\ ${ }^{\prime}$ Department of Anatomy, Faculty of Medicine, University of Ruhuna, Galle. \\ ${ }^{2}$ Base Hospital Tissamaharama, Tissamaharama.
}

\section{Introduction}

Kidney to body height ratio (KBR) is considered as a better parameter compared to absolute renal length (RL) in renal size evaluation. Ethnic variations are described for renalsizes. Studies pertaining to renal length are scares for Sri Lankan population. Current study was conducted to evaluate RL and KBR for a group of Sri Lankan adults.

\section{Methodology}

Healthy adults presented for medical check-ups were recruited by random sampling method. Subjects with previous renal surgeries, renal disease or other chronic illnesses were excluded. Personal height was measured with a stediometer. Renal length was measured sonographically by a single Radiologist with $3.5 \mathrm{MHz}$ probe. One-way ANOVA was conducted to compare the effect of gender on KBR and RL.

\section{Results}

The study population $(\mathrm{n}=215)$ consisted of adult females $(\mathrm{n}=110)$ and males $(n=115)$. Mean age was 24 years (19 -36 years). Mean height was; male $(166.79 \pm 6.3 \mathrm{~cm})$, female $(156.49 \pm 6.3$ $\mathrm{cm})$. Mean RL-right kidney was $9.77 \pm$
$0.78 \mathrm{~cm}$ and RL-left kidney was $10.16 \pm 0.83 \mathrm{~cm}$. Mean KBR of the right kidney was $0.60 \pm 0.05 \mathrm{~mm} / \mathrm{cm}$ and left kidney was $0.63 \pm 0.05 \mathrm{~mm} / \mathrm{cm}$. The left RL and KBR were higher than those of the right side irrespective of gender $(p<0.001)$. Gender effect was more significant for KBR bilaterally (F$20.3=1.213 ; \mathrm{p}<0.001)$ compared to RL.

\section{Discussion and Conclusions}

Absolute renal length shows a better representation of renal size for the study sample with minimum gender effect. This preliminary study is the first step in establishing reference ranges for RL and KBR for a Sri Lankan population. Such data will be of value in diagnosing renal pathologies. 